\title{
Duas espécies novas de Lophoblatta (Blattellidae, Pseudophyllodromiinae) coletadas na Mata Atlântica, Rio de Janeiro
}

\author{
Sonia Maria Lopes \& Edivar H. de Oliveira
}

Museu Nacional, Departamento de Entomologia, Quinta da Boa Vista, São Cristóvão, 20940-040 Rio de Janeiro, Brasil. (sonialfraga@gmail.com)

\begin{abstract}
Two new species of Lophoblatta (Blattellidae, Pseudophyllodromiinae) collected in the Atlantic forest, Rio de Janeiro, Brazil. In this paper Lophoblatta leuropeltiana sp. nov. and L. tijucana sp. nov. are described from Rio de Janeiro with illustrations of male and female genitalia.
\end{abstract}

KEYWORDS. Blattaria, diversity, taxonomy.

RESUMO. São descritas Lophoblatta leuropeltiana sp. nov. e L. tijucana sp. nov. do Rio de Janeiro, com ilustrações da genitália dos machos e da fêmea.

PALAVRAS-CHAVE. Blattaria, diversidade, taxonomia.

Lophoblatta Hebard, 1929 caracteriza-se por indivíduos de porte pequeno a médio, variando de 10 a $30 \mathrm{~mm}$, de coloração amarela brilhante, contorno arredondado, alargados, com pronoto reto na base e contorno subparabólico. No fêmur anterior apresentam uma série decrescente de espinhos, caracterizando o tipo A3 finalizados por três espinhos apicais (Rотн, 2003). No abdome é evidenciada a modificação tergal somente no sétimo segmento ou no sétimo e oitavo concomitantes representada por um grupo de cílios concentrados na região mediana; a placa subgenital larga, simétrica ou suavemente assimétrica, apresentando estilos simples, com cílios na extremidade distal. Na genitália do macho, o esclerito mediano configura-se bifurcado com espinhos ou não (LoPES \& Oliveira, 2003).

Atualmente são conhecidas onze espécies que ocorrem na maioria dos países da América do Sul, com exceção de Chile, Bolívia e Argentina, bem como em países da América Central. No Brasil distribuem-se desde o norte até os estados do sudeste. Têm preferência por bromélias, podendo ser encontradas também em folhiço no interior de matas.

Neste trabalho duas novas espécies de Lophoblatta são descritas e ilustradas.

\section{MATERIAL E MÉTODOS}

Um dos exemplares estudado neste trabalho foi coletado em folha de imbaúba seca, em uma área de proteção ambiental da floresta da Tijuca denominada Reserva Florestal da Vista Chinesa, atualmente Unidade de Conservação, sob a jurisdição da Fundação Estadual de Engenharia do Meio Ambiente (FEEMA). Esta Reserva compreende uma área de 15 hectares, localizada no km 2 da Estrada da Vista Chinesa, Alto da Boa Vista, no município do Rio de Janeiro e situa-se na Serra da Carioca, no maciço da Tijuca, na encosta sul dos morros da Freira e Boa Vista, latitude $22^{\circ} 52^{\prime} \mathrm{S}$, longitude $46^{\circ} 15^{\prime} \mathrm{W}$ e altitude entre 340 e $586 \mathrm{~m}$, em terrenos litologicamente de rochas do arqueano, principalmente gnaisse (CARAUTA et al., 1994).

Em laboratório, após a triagem, os exemplares das duas espécies foram montados e etiquetados com dados relacionados à localidade, data e coletor.

A observação das placas genitais foi feita através da retirada da parte final do abdome do exemplar macho, designado como holótipo, utilizando-se técnicas tradicionais para dissecção (LOPES \& OlIVEIRA, 2000). A designação das peças genitais foi baseada nos conceitos propostos por RoTH (2003).

Após análise, as placas e peças genitais foram guardadas em microtubo de vidro contendo glicerina e acondicionadas junto ao exemplar respectivo. Todo o material encontra-se depositado na coleção do Museu Nacional do Rio de Janeiro (MNRJ).

\section{Lophoblatta leuropeltiana sp. nov.} (Figs. 1-10)

Etimologia. O nome da espécie refere-se à sua semelhança fenotípica com indivíduos do gênero Leuropeltis Hebard, 1921.

Coloração castanha brilhosa. Pronoto castanhoclaro hialino com faixa central castanho-escura larga, longitudinal e convergente em direção ao ápice. Cabeça enegrecida; faixa estreita transversal castanho-amarelada entre o espaço interocular e a fronte unindo as bases das inserções das antenas; ocelos avermelhados; antenas e palpos com tomentosidade dourada. Tégminas e pernas escuras; pulvilos castanho-esbranquiçados.

Cabeça subtriangular; vértice exposto sob o pronoto, em vista dorsal; espaço interocular amplo, medindo cerca de $80 \%$ da área que separa as bases de inserção das antenas; palpos maxilares e antenas tomentosos; estas longas, ultrapassam em comprimento o ápice dos cercos; terceiro artículo maior que os demais; quinto artículo dilatado. 
Pronoto elíptico, transverso, convexo, com base e ápice retos; abas laterais amplas e com contorno arredondado. Pernas espinhosas; fêmur da perna anterior, na face ântero-ventral, com três espinhos grandes e espaçados da base até próximo à região mediana, sucedidos por uma série de onze espinhos que decrescem gradativamente em direção ao ápice, e mais três espinhos apicais grandes; face póstero-ventral com cinco espinhos grandes e espaçados, sendo um deles apical. Fêmures das pernas mediana e posterior com seis a oito espinhos grandes e espaçados, sendo um deles apical; condição semelhante em ambas as faces ventrais; pulvilos presentes em todos os artículos tarsais; unhas simétricas e especializadas, com seis a oito dentículos ventrais. Tégminas longas, ultrapassando em comprimento o ápice dos cercos; campo marginal defletido, amplo e curto, com disposição das veias oblíqua; campo discoidal convexo, com disposição das veias longitudinal; campo anal longo e amplo com seis ou mais veias axilares. Asas com setor costal apresentando os ápices dos ramos da veia radial pouco dilatados; triangulo apical pequeno e campo anal dobrado em leque.

Abdome. No macho, a modificação tergal no sétimo segmento medianamente em forma de duas fileiras verticais simétricas e paralelas de cílios pequenos, direcionados para o meio do segmento (Fig. 1). Placa supra-anal curta, ciliada e projetada entre os cercos; paraproctos distintos; cercos alargados, desenvolvidos e tomentosos (Fig. 2). Placa subgenital alargada médioapicalmente, com estilos simples inseridos em uma pequena reentrância mediana, com pequenos espinhos apicais (Fig. 3). Na fêmea, placa supra-anal pronunciada entre os cercos com reentrância acentuada medianamente (Fig. 4); placa subgenital elipsóide (Fig. 5).

Genitália. No macho, esclerito mediano bífido com o braço esquerdo afilado apicalmente, assemelhando-se a um espinho; expansão lateral acima da metade do esclerito com ápice modificado apresentando espinhos apicalmente (Fig. 6). Falômero esquerdo com os braços assimétricos, um deles bastante desenvolvido e afilado apicalmente; estrutura mediana alargada, com o bordo apical fortemente esclerotinizado e modificado em dois grupos de espinhos (Fig. 7). Falômero direito em forma de gancho com a extremidade espiniforme (Fig. 8). Esclerito bífido, sendo um dos braços afilado até o ápice (Fig. 9). Na fêmea, válvulas diferenciadas em forma e tamanho; valvíferos reduzidos; paratergitos desenvolvidos (Fig. 10).

Dimensões, em mm. Holótipo ơ: comprimento total 26,0; comprimento das tégminas 21,0; largura da tégmina 8,0 ; comprimento do pronoto 6,0; largura do pronoto 9,0; espaço entre as bases das antenas 1,5.

Dimensões, em mm. Parátipo o (Mangaratiba): comprimento total 20,0; comprimento do pronoto 6,0 ; largura do pronoto 7,0; comprimento das tégminas 18,0 ; largura das tégminas 6,0. Parátipo $\$$ (Tijuca): comprimento total 26,0; comprimento do pronoto 5,0; largura do pronoto 9,0 ; comprimento das tégminas 21,0 ; largura das tégminas 8,0 .

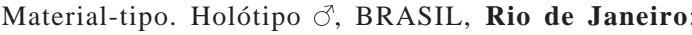
Tijuca, s/data, s/coletor. Parátipos, 2 + , dados iguais ao holótipo; Mangaratiba, Alminha, o', $\odot$, V.1968, L. Gomes col.; Piloto Itavera, ơ, , X. X.1968, L. Gomes col.; Parque Nacional de Itatiaia, Lago Azul, O’, 17.X.1962, J. Becker col.; Parque Nacional da Serra dos Órgãos, + , VI.1981, Gustavo col.

Comentário. A espécie pode ser inserida no grupo I de Lophoblatta (Lopes \& OLIVEIRA, 2003) pelo tipo de modificação tergal no sétimo segmento, porém dele diferencia-se pela configuração do esclerito mediano e do falômero esquerdo.

\section{Lophoblatta tijucana sp. nov.}

(Figs. 11-16)

Etimologia. O nome da espécie refere-se ao nome da localidade onde foi coletado o exemplar.

Descrição. Holótipo ơ. Coloração geral castanhoclara brilhante. Pronoto hialino com disco central leitoso, apresentando pontos negros e esparsos. Cabeça com duas faixas transversais castanho-escuras, uma entre os olhos e outra entre os ocelos; presença de pontuações espaçadas castanho-enegrecidas; antenas e palpos maxilares com tomentosidade dourada; olhos castanhos. Tégmina hialina com o campo anal e discoidal castanho mais escurecido. Asas esbranquiçadas. Coxas e ponto de inserção dos espinhos dos fêmures médio e posterior, castanho-escuros.

Cabeça triangular, vértice exposto sob o pronoto; espaço interocular amplo, subigual em tamanho à área que separa as bases das inserções antenais; antenas longas e tomentosas, ultrapassando em comprimento o ápice do abdome; palpo maxilar com o terceiro, quarto e quinto artículos alongados, sendo este último dilatado e tomentoso.

Pronoto convexo, sub-trapezoidal, com ápice e base retos e abas laterais amplas e arredondadas. Pernas desenvolvidas e espinhosas, fêmur anterior com a face ântero-ventral apresentando uma série de espinhos que decrescem gradativamente da base em direção ao ápice, terminando em três apicais robustos; face póstero-ventral com quatro espinhos robustos e espaçados. Fêmures médio e posterior, na face ântero-ventral, com seis a sete espinhos grandes e espaçados, sendo um apical; face póstero-ventral com quatro a cinco espinhos grandes e espaçados, sendo um apical. Presença de espinho genicular. Unhas simétricas e especializadas com seis a oito dentes ventrais. Pulvilos em todos os artículos e arólios presentes. Unhas simétricas e especializadas. Tégminas ultrapassando em comprimento o ápice dos cercos; campo marginal curto e defletido; campo escapular amplo, alongado, com disposição oblíqua das veias; campo discoidal com veias em disposição longitudinal e campo anal amplo e alongado. Asas com setor costal, com ápices dos ramos da veia radial não dilatados; triângulo apical pequeno e campo anal dobrado em leque.

Abdome. Modificação tergal no sétimo segmento medianamente em forma de duas fileiras verticais simétricas e paralelas de cílios pequenos (Fig. 11). Placa supra-anal curta, ciliada e projetada entre os cercos; 
paraproctos distintos, cercos alargados, desenvolvidos e tomentosos (Fig. 12). Placa subgenital alargada médioapicalmente, com estilos simples inseridos em uma pequena reentrância mediana, com pequenos espinhos apicais (Fig. 13).

Genitália. Esclerito mediano bífido com o braço esquerdo afilado apicalmente, expansão lateral acima da metade do esclerito com ápice modificado apresentando espinhos apicalmente (Fig. 14). Falômero esquerdo com os braços assimétricos, um deles bastante desenvolvido; estrutura mediana alargada apicalmente, fortemente esclerotinizada e modificada em espinhos (Fig. 15). Falômero direito em forma de gancho com a extremidade espiniforme (Fig. 16).

Dimensões, em mm. Holótipo ơ: comprimento total
17,0 ; comprimento do pronoto 4,0 ; largura do pronoto 6,0; comprimento da tégmina 15,0; largura da tégmina 5,0; área que separa as bases das inserções antenais 1,0.

Material-tipo. Holótipo ơ, BRASIL, Rio de Janeiro: Floresta da Tijuca, coletado em folha de imbaúba seca, próximo à sede da FEEMA, 15.III.2005, Edivar H. Oliveira col.

Comentário. A espécie pode ser inserida no grupo I de Lophoblatta (Lopes \& OliveIRA, 2003) pelo tipo de modificação tergal no sétimo segmento, porém dele diferencia-se pela configuração da placa subgenital, com leve reentrância mediana entre os estilos, e o esclerito mediano apresentando espinho apicalmente e a haste levemente afilada apicalmente e pela configuração do falômero esquerdo.
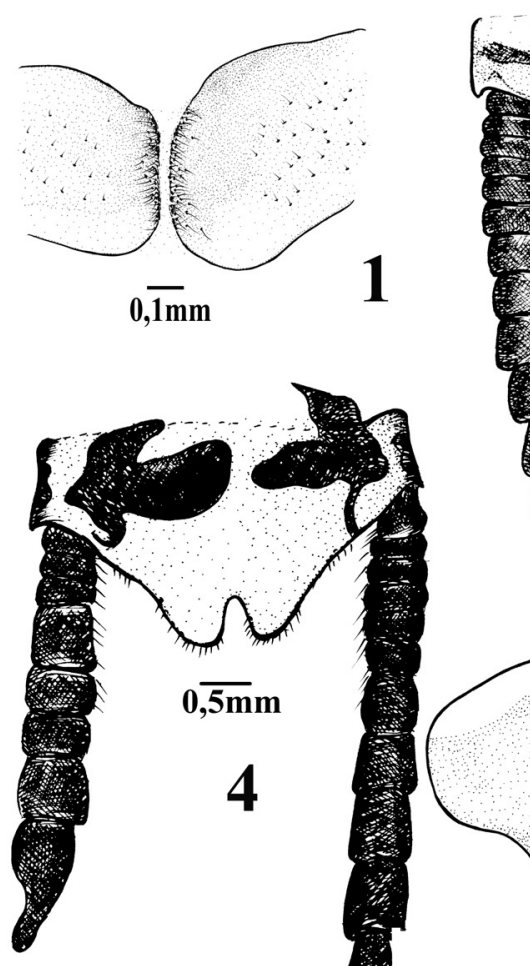

\section{falonero esquerdo.}



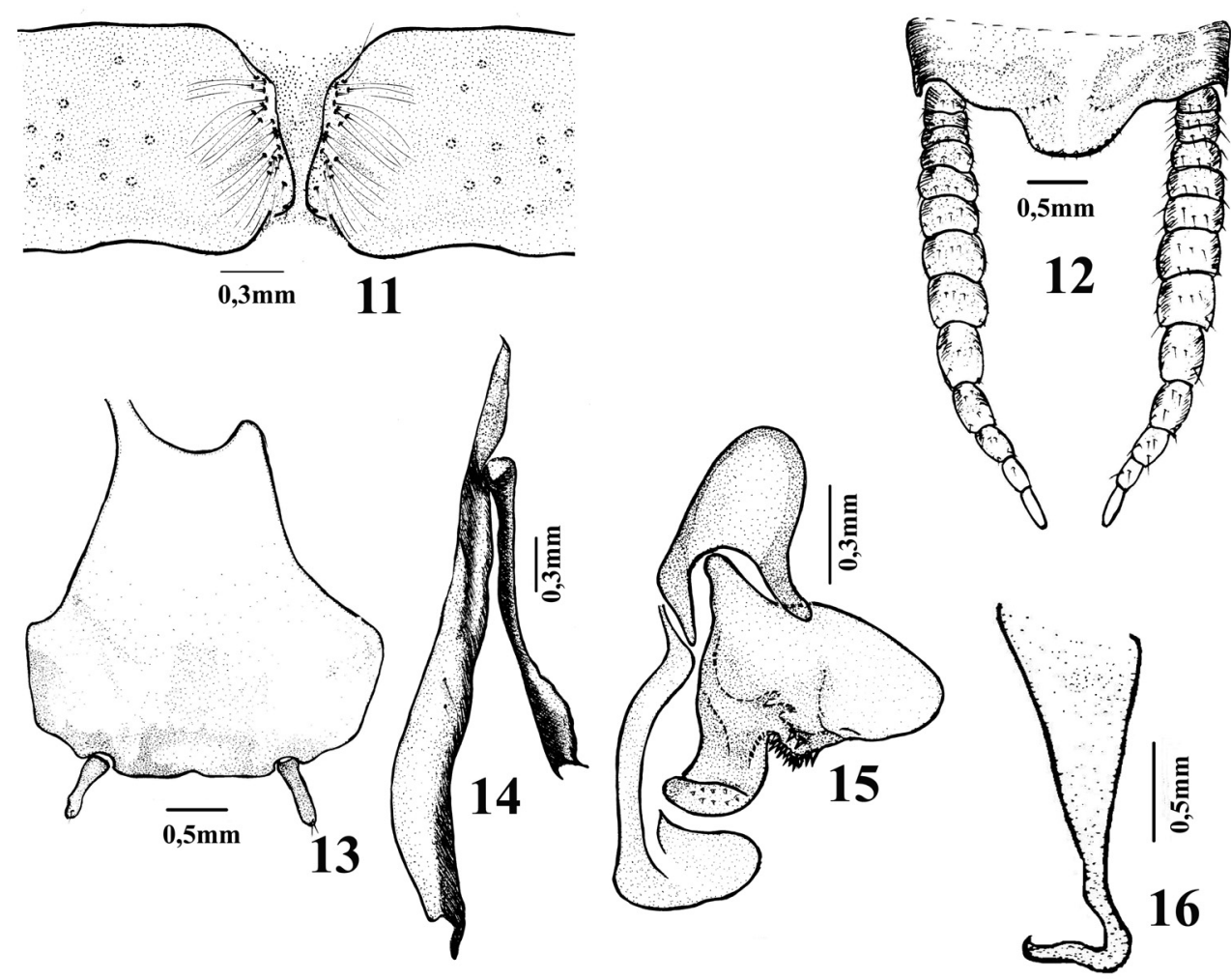

Figuras 11-16. Lophoblatta tijucana sp. nov. Holótipo ơ': 11, modificação tergal no sétimo segmento do abdome, dorsal; 12 , placa supraanal, dorsal; 13, placa subgenital, ventral; 14, esclerito mediano, ventral; 15, falômero esquerdo, ventral; 16, falômero direito, ventral.

Agradecimentos. Ao CNPq, pela concessão de bolsa de produtividade em pesquisa ao autor sênior.

\section{REFERÊNCIAS BIBLIOGRÁFICAS}

Carauta, J. P. P.; Vianna, M. C.; Oliveira, R. R. de; Magnanini, A.; Martins, H. F.; Lima, D. F.; Silva, D. C. P. Da \& Oliveira, C. A L. DE. 1994. Reserva Florestal "Vista Chinesa", Rio de Janeiro. Lista de Gêneros. Albertoa 3(21):229-240.
Lopes, S. M. \& Oliveira, E. H. 2000. Espécie nova de Eublaberus Hebard, 1919 do Estado de Goiás, Brasil e notas sobre E. marajoara Rocha e Silva-Albuquerque, 1972 (Blaberidae, Blaberinae). Boletim do Museu Nacional, Nova Série, Zoologia 433:1-5.

2003. Duas espécies novas de Lophoblatta (Blattaria, Blattellidae) do Brasil e descrição da genitália de cinco espécies conhecidas. Iheringia, Série Zoologia 93(4):341-354.

Rотн, L. M. 2003. Systematics and phylogeny of cockroaches (Dictyoptera: Blattaria). Oriental Insects 37:1-186. 